\title{
Original DOCETAXEL, DOXORUBICIN AND CYCLOPHOSPHARMIDE AS Article NEOADJUVANT CHEMOTHERAPY WITH PRIMARY PROPHYLACTIC STEM CELL GROWTH FACTOR SUPPORT IN LOCALLY ADVANCED BREAST CANCER (T3 - T4, NO - 3, MO)
}

\author{
Ehab Elnakory ${ }^{1}$, Samiah Abdulrazek ${ }^{2}$, Ashraf Fawzy ${ }^{3}$ \\ ${ }^{1}$ Kasr EL-Aini Center of Clinical Oncology, ${ }^{2}$ Pathology Department ,Faculty of Medicine Cairo \\ University ${ }^{3}$ Surgery Department, Faculty of Medicine, Ain Shams University.
}

\begin{abstract}
Aim of the Work: To assess the efficacy and the toxicity of combination of docetaxel, doxoribicin and cyclophosphamide as neodjuvant chemotherapy with prophylactic stem cell growth factor support in locally advanced breast cancer.

Patients and Methods: 23 patients with stages IIB and III breast cancer received three to four cycles of neodjuvant decetaxel $75 \mathrm{mg} / \mathrm{m}^{2}$, doxorubicin $50 \mathrm{mg} / \mathrm{m}^{2}$, and cyclophosphamide $500 \mathrm{mg} / \mathrm{m}^{2}$ (TAC) on day 1 , intravenously on a $21-$ days cycle as well as granulocyte colony stimulating factor (G-CSF) 300 micro gm. subcutaneously daily for 5-7 days starting on day two, also cibrofloxacine 500mg orally every 12 hours for 5-10 days starting on day five of each cycle.

Results: A total of 23 patients with a median age of 42 years (range 32-57 years), were assigned to receive 3-4 cycles of neoadjuvant TAC regimen and primary prophylaxis with G-CSF.16 out of the twenty three patients were stage III B. A total of 86 cycles were given. The overall clinical response rate among the whole group was $91.3 \%$, nine patients obtained complete cCR (39.1\%), and twelve patients obtained cCR (52.2\%), while complete pathological response (p $\mathrm{CR}$ ) were confirmed in four (17.4\%) patients and microscopic residuals were detected in the breast in three cases and in the axillary lymph nodes in four cases. The treatment was generally safe, well tolerated, there were no cases that needed hospitalization because of toxicity related event.

Conclusion: The combination of docetaxel, doxorubicin and cyclophosphamide with granulocyte colony stimulating factor as given in this study is safe, tolerable and shows good activity in the neoadjuvant setting for locally advanced breast cancer stages IIB to III patients.
\end{abstract}

Key Words: Breast, cancer-neoadjuvant, chemotherapy

\section{INTRODUCTION}

The use of anthracylines in combination therapy is superior to the use of non anthracycline-containing regimens. Anthracyclines have become a key component of routine care for patients with breast cancer ${ }^{1}$.

Combination anthracycline-docetaxel regimens are well studied in the setting of metastatic breast cancer; although they are highly myelosuppressive, they produce acceptable levels of cardiotoxicity and are highly $\operatorname{active}^{2,3}$.

Neoadjuvant chemotherapy (NC), also referred as preoperative, induction or primary chemotherapy, has become established as standard option on the multidisciplinary management of patients with Locally Advanced Breast Cancer (LABC). This approach permits a down stage of the primary tumor, facilitates radical locoregional treatments and increases the rates of breast conversing surgery without compromising survival ${ }^{4}$.

Neoadjuvant chemotherapy provides an effective means to test individual chemo-sensitivity in vivo and might eradicate occult distant metastasis. So, achievement of the best clinical response and finally a pathological complete response (PCR) is the main target of neoadjuvant chemotherapy. Although initial randomized trials did not clearly demonstrate survival advantage over adjuvant chemotherapy $^{5,6}$. It seems that patients who achieve a PCR after induction chemotherapy obtain a benefit on survival ${ }^{7,8}$.

And currently, many studies are going on to confirm such concept. 
The use of taxanes in patients with advanced breast cancer who have failed treatment with anthracyclinebased regimens has resulted in overall response rates of $18 \%$ to more than $50 \%{ }^{9,10}$.

Docetaxel, in particular, was shown in two phase II studies to induce responses in over $50 \%$ of patients with anthracycline - resistant breast cancer ${ }^{11,12}$.

Thus, it is our interest in this study to add docetaxel in combination to $\mathrm{AC}$ regimes on day one with primary prophylaxis with granulocyte colony stimulating factor (G-CSF). That might increase clinical and pathological complete response rates when given as primary systemic chemotherapy in patients with locally advanced breast cancer so that to shorten the over all treatment in three to four weeks - 21 days cycles (6-9 weeks). Than other protocols using sequential regimen for a total of eight cycles in 6-9 weeks.

\section{PATIENTS AND METHODS}

All female patients with histologically confirmed clinical, stage, IIB to III invasive, breast cancer, were included in this study. They were all $>18$ years and had to have Eastern Cooperative Oncology Group performance status $<2$. Full laboratory tests in the form of adequate blood counts, hepatic and renal profiles were confirmed. Staging work-up included chest radiography abdomino-pelvic ultrasound and isotopic bone scan. Measurable disease was required by physical examination or radiological imaging including mammography and complementary breast ultrasound. Clinical and pathological tumor size - node - metastasis (T-N-M) staging system was based on the American Joint Committee on Cancer Staging Manual (AJCC) ${ }^{13}$. Immuno-histochemical staining was done in all cases for estrogen (ER) and progesterone $(\mathrm{PgR})$ Receptors. Her $-2 /$ neu status was evaluated in all cases by immuno histochemistry (IMC) only.

\section{Treatment Plan:}

All patients received 3 to 4 cyclic systemic intravenous (I.V.) combination neoadjuvant TAC regimen. Docetaxel $75 \mathrm{mg} / \mathrm{m}^{2}$, Doxorubicin $500 \mathrm{mg} / \mathrm{m}^{2}$ and cyclophosphamide $500 \mathrm{mg} / \mathrm{m}^{2}$ on day one every three weeks. All patients were required to receive premdication regimen before each cycle that initially consisted of dexamethazone $12 \mathrm{mg}$, ranitidine $50 \mathrm{mg}$, ondansetron or grainsetron $1 \mathrm{mg}$ or $8 \mathrm{mg}$, respectively added to $50 \mathrm{cc}$ saline or glucose $5 \%$ I.V. over 30 minutes, uromitexan $400 \mathrm{mg}$ I.V. bolus and diphenhydramine $50 \mathrm{mg}$ I.V. or allerfin $1 \mathrm{mg}$ I.M. The latter was given about one hour before taxotere infusion.

Post medication regimen included low doses of dexamethazone $8 \mathrm{mg}$ /day devided on two doses after meals,ranitidine $150 \mathrm{mg}$ once daily before bed time with proton pump inhibitor in the morning for three days, grainsetron $16 \mathrm{mg}$ /day for one day to be followed by metoclopromide orally for three days. Primary prophylaxis with $\mathrm{G}-\mathrm{CSF} 300 \mu \mathrm{mg}$ subcutaneously was started 24 hours after finishing chemotherapy regimen, daily for 5-7 days as well as cibrofloxacine 500mg orally every 12 hours for 5-10 days. Starting on day five. Patients received three or four cycles of chemotherapy according to the speed of response as well as concerns of clinical stage. After neoadjuvant chemotherapy, evaluation of response was made and the type of locoregional treatment was decided according to response whether to be subjected to surgery or not.

Non responder patients were planned to recieve second-line chemotherapy and radiotherapy.

After surgery, patients received two to three cycles of adjuvant chemotherapy. Patients with minor or no response received second line chemotherapy the rest of the patients completed two or three cycles of the same neoadjuvant chemotherapy regimen.

All patients were planned to adjuvant external beam radiation therapy adjuvant hormonal therapy was stared at the end of adjuvant chemotherapy for those with positive hormone receptor tumors.

\section{Safety Assessments:}

Adverse events were assessed every week for the duration of the study and graded according to the National Cancer Institute of Canada Common Toxicity Criteria (NCIC-CTC), version 2.0 ${ }^{14}$. Data on serious adverse events were collected throughout the study. Laboratory assessment of blood counts; hepatic and renal profiles were done before each cycle and if clinically indicated. Baseline left ventricular ejection fraction was assessed by echocardiography and had to be more than $50 \%$.

\section{Efficacy Assessments:}

\section{A-Assessment of clinical response:}

Clinical response was assessed following the first cycle and before each following cycle by physical examination. After neoadjuvant treatment response was evaluated clinically and with diagnostic breast imaging. Response was evaluated according to the World Health Organization Criteria; clinical complete (cCR) was defined as the absence of tumor in the breast and regional lymph nodes by clinical examination and diagnostict breast imaging. The response was judjed to be partial (cPR) when the reduction of the breast tumor was $50 \%$ or more. Increase of more than $25 \%$ in the size of tumor or unequivocal appearance of new lesions was defined as progressive disease (cPD). While those patients whose tumor did not meet the definition of $\mathrm{cCR}$, $\mathrm{CPR}$ or $\mathrm{CPD}$ were considered 
to have stable disease (cSD).

\section{$B$-Assessment of pathological response:}

Complete pathological response was considered (pCR) If there were no viable tumor cells on the examined breast and lymph nodes. While minimal residual disease (MRD) was considered if there were microscopic foci of tumor cells in the breast tumor or in the axillary lymph nodes on the examined specimen.

\section{RESULTS}

\section{Patients Demographics:}

Between March 2004 and July 2006, twenty three

Table 1: Patients Characteristics $(\mathrm{n}=23)$.

\begin{tabular}{|c|c|c|}
\hline Characteristic & Number & Percentage \\
\hline \multicolumn{3}{|l|}{ Age } \\
\hline Median & 42 & \\
\hline Mean & 42.9 & \\
\hline Range & $32-57$ & \\
\hline \multicolumn{3}{|l|}{ Menopausal status } \\
\hline Pre Menopausal & 16 & 69.5 \\
\hline Post Menopausal & 7 & 30.4 \\
\hline \multicolumn{3}{|l|}{ Tumor size (cm) } \\
\hline Mean & 7.6 & \\
\hline Range & $4-13$ & \\
\hline Clinical Status & 5 & \\
\hline $\mathrm{T} 3$ & 18 & 21.7 \\
\hline $\mathrm{T} 4$ & & 78.7 \\
\hline \multicolumn{3}{|l|}{$\begin{array}{l}\text { Clinical Nodal } \\
\text { Status }\end{array}$} \\
\hline $\mathrm{N} 0$ & 8 & 34.8 \\
\hline N 1 & 1 & 4.3 \\
\hline $\mathrm{N} 2$ & 13 & 56.5 \\
\hline N 3 & 1 & 4.3 \\
\hline \multicolumn{3}{|l|}{ Clinical Stage } \\
\hline II B & 3 & 13.1 \\
\hline III A & 3 & 13.1 \\
\hline III B & 16 & 69.6 \\
\hline III C & 1 & 4.3 \\
\hline I BC & 3 & 13 \\
\hline \multicolumn{3}{|l|}{$\begin{array}{l}\text { Hormone Receptor } \\
\text { Status }\end{array}$} \\
\hline $\begin{array}{l}\mathrm{ER}+\text { ve and/or } \\
\mathrm{PgR}+\mathrm{ve}\end{array}$ & 19 & 82.6 \\
\hline ER and $P g R-v e$ & 4 & 17.4 \\
\hline \multicolumn{3}{|l|}{ HER-2/neu Status } \\
\hline- ve & 15 & 65.2 \\
\hline$+\mathrm{ve}$ & 8 & 34.8 \\
\hline
\end{tabular}

ER: Estrogen Receptor, PgR: Progesterone receptor. HER -2: Human epidermal growth factor receptor. IBC:Inflammatory breast cancer. patients were enrolled in this study. Patient characteristics at the time of entering the study are listed in the Table1.

The mean age of the patients was 42.9 years (Range 32-57 years). Eighteen patients (78.3\%) had T4 status while $21.7 \%$ (five patients) had T3 status at presentation.

Fifteen patients $(65.2 \%)$ had clinically positive lymph nodes $(4.3 \% \mathrm{~N} 1,56.5 \% \mathrm{~N} 2$ and $4.3 \% \mathrm{~N} 3)$.

Three patients were staged as IIB and the remaining twenty were stage III; $13 \%$ of the later were stage IIIA, $69.6 \%$ were stage III B which constitute the majority of the cases (16) and $4.3 \%$ (one patient) was stage IIIC. It is to be noted that there were three cases $(13 \%)$ out of the whole group presented with inflammatory breast cancer (IBC).

\section{Neoadjuvant Chemotherapy:}

A total of 86 cycles were administered in this study. Six cases received 3 cycles of neoadjuvant chemotherapy and seventeen cases received four cycles (Table 2). Because of cancers of clinical stage and speed of response.

All patients received chemotherapy regimen at full prescribed doses, no dose reduction occurred. Delay of one week of the treatment was needed for three patients where as 20 patients finished their treatment without any delay.

Table 2: Number of Neo adjuvant chemotherapy cycles in relation to the clinical stage $(n=23)$

\begin{tabular}{lcc}
\hline Clinical stage & No of Patients & No of cycles gives \\
\hline \multirow{2}{*}{ II B } & 2 & 3 \\
& 1 & 4 \\
III A & 2 & 3 \\
& 1 & 4 \\
III B & 2 & 3 \\
& 14 & 4 \\
III C & 1 & 4 \\
\end{tabular}

\section{Clinical Response:}

The overall clinical response rate among the 23 patients was $91.3 \%$. 9 patients obtained a cCR (39.1\%) and 12 patients obtained cPR (52.2\%). Stable disease was observed in two patients $(8.7 \%)$ while non of the whole group of patients experienced diseases progression (Table 3 ). The combined clinical response includes physical examination as well as mammography/ultra songraphy. 
Table 3: Clinical and Pathological responses to Neoadjuvant TAC regimen $(n=23)$.

\begin{tabular}{lcc}
\hline Characteristic & No. & Percentage \\
\hline Clinical Response & 9 & 39.1 \\
Complete & 12 & 52.2 \\
Partial & 2 & 8.7 \\
Stable & - & - \\
Progressive & 21 & 91.3 \\
Over all response rate & & \\
Pathological Response & 4 & 17.4 \\
Complete & & 13 \\
Microscopic Residuals & 3 & 17.4 \\
In Primary tumor & 4 & \\
In axillary lymph nodes & &
\end{tabular}

\section{Surgical Treatment:}

After neoadjuvant chemotherapy, all the patients had undergone surgery. Breast conservation surgery including axillary lymph nodes dissection was done in 14 patients $(60.9 \%)$ while the reaming 9 cases $(39.1 \%)$ had undergone modified radical mastectomy including the three cases with inflammatory breast cancer at presentation.

\section{Pathological Responses:}

The whole group of patients were evaluated for pathological response after neoadjuvant chemotherapy and surgery where complete pathological response was obtained in foudszr cases $(17.4 \%)$ both in the primary tumor as well as in the axillary lymph nodes where tumoral necrosis, surrounded by active fibroblastic tissue with excess aggregates of foamy and hemosiderin- laden histiocytes constituted the microscopic pictures in the pathological specimens.

Residuals were present in 7 cases $(30 \%)$; three of them showed residuals in the primary tumor and four cases showed residuals in the axillary lymph nodes. So, a total of 11 cases $(47.8 \%)$ achieved favorable pathological response including complete pathological responses and microscopic residuals.

\section{Toxicity:}

A total of 86 cycles of TAC regimen were given to the whole study group with primary prophylaxis with Granulocyte Colony Stimulating Factor ( $\mathrm{G}-\mathrm{CSF}$ ) and cibrofloxacine. The treatment was generally well tolerated There were no cases that needed hospitalizations because of toxicity related events: toxicity data for the whole group of patients according to the criteria of NCIC-CTC, version- 2 is summarized in table 4 .

Table 4: Toxicity profile according to NCIC-CTC $(n=23)$.

\begin{tabular}{lcc}
\hline Toxicity & \multicolumn{2}{c}{ NCIC Grade No. of Patients (\%) } \\
& $\mathbf{1}$ & $\mathbf{2}$ \\
\hline Hematological & & $1(4.3)$ \\
Leukopenia & $2(8.7)$ & $1(4.3)$ \\
Neutropenia & $1(4.3)$ & $3(13)$ \\
Anemia & $6(2.6)$ & \\
Thrombocytopenia & & \\
Castro-Intestinal & & $4(17)$ \\
Nausea-vomiting & $1(4.3)$ & $3(13)$ \\
Constipation & $2(8.7)$ & $5(22)$ \\
Skin & & $4(17)$ \\
Pigmentation & $16(70)$ & $5(22)$ \\
Nail changes & $7(30)$ & \\
Peripheral & $6(26)$ & \\
Neuropathy & & $8(35)$ \\
Allergic reaction & & $4(17)$ \\
Musculoskeletal & & \\
bony pains & $13(57)$ & $4(17)$ \\
Fatigue & & \\
* NCIC-CTC National Cancer Institute of canada common toxicity \\
criteria
\end{tabular}

\section{DISCUSSION}

Primary end points in phase II trials of neoadjuvant chemotherapy for breast cancer are usually clinical and pathological response. Clinical response rates are in the range of $60 \%-90 \%$ and it has been correlated with outcome ${ }^{15}$. This wide range may reflect the disconcordance between physical examination and diagnostic breast imaging in predicting response to neoadjuvant chemotherapy. In this study, we reported three cases out of the nine that experienced complete clinical response had residual lesions by breast imaging (mammography or ultrasound), on the other hand, those cases that showed complete radiological responses were confirmed by clinical examination.

Achievement of pCR should be the main goal of neoadjuvant chemotherapy however the proportion of patients whose tumors disappeared completely on histopathological examination after primary systemic chemotherapy and who therefore had an expectation of a good outcome, has been disappointingly low. Skipper ${ }^{16}$ proposed that micrometastatic clones of cancer cells would likely not respond to systemic treatment in the same way as the primary tumor but the results of the B- 
18 trial and other primary systemic chemotherapy studies indicate that this hypothesis is incorrect ${ }^{8,17}$.

The rate of pCR to neoadjuvant chemotherapy with new combinations is in the range of $10 \%$ to $30 \%$. These differences between the studies concerning of pCR are difficult to interpret because of lack of universally pathological response classification system used among different studies ${ }^{18-21}$ where some studies reported pCR in the breast only, others include cases of carcinoma in situ in the $\mathrm{pCR}$ and rarely to refer pCR to both the primary breast tumor and axillary lymph nodes. Herein this study we reported pCR in both breast and axillary lymph nodes in four bout of the 23 cases $(17.4 \%)$ which is comparable to that reported by Aguiar et al. ${ }^{22}$ when using Epirubicin, cyclophosphamide and weekly paclitaxel as neoadjuvant treatment where they reported $(15.1 \%)$ pCR but lower than that was reported by Marjorie et al. ${ }^{23}$ when using weekly paclitaxel followed by FAC with $28.2 \%$ pCR which may be explained by the fact that most of their patients were staged II (84\%) while most of our patients in this study were stage III $(87.0 \%)$. The largest phase III study, NSABP-27, compared patients receiving docetoxel (D) once every three weeks for four cycles after four cycles of doxorubicin and cyclophosphamide (AC) with patients who only received four cycles of AC. Patients receiving $\mathrm{AC}$ followed by $\mathrm{D}$ achieved a pCR of $25.6 \%$ in the breast alone compared with a pCR of $13.7 \%$ for patients receiving only $\mathrm{AC}$ regime ${ }^{24}$, however, residual disease in the axilla can negatively predict survival ${ }^{25}$.

We found a trend to a better response in patients with Her-2/neu negative and hormone-receptor positive tumors (Table 5).

Table 5: Correlation between favorable pathological response (pCR and microscopic residuals) and Hormone receptor, Her-2/neu ststus ( $\mathrm{n}=23$ patients).

\begin{tabular}{|c|c|c|c|c|}
\hline & \multirow{2}{*}{$\begin{array}{c}\text { ER \& PgR } \\
+ \text { ve/ Her- } \\
\text { 2/neu-ve }\end{array}$} & \multicolumn{2}{|c|}{ ER and / or PgR + ve } & \multirow{2}{*}{$\begin{array}{l}\text { ER \& \& } \\
\text { PgR - ve } \\
\text { / H e r - 2 / } \\
\text { neu-ve }\end{array}$} \\
\hline & & $\begin{array}{c}\text { Her-2/neu } \\
\text { - -ve }\end{array}$ & $\begin{array}{c}\text { Her-2/neu } \\
+ \text { ve }\end{array}$ & \\
\hline $\mathrm{pCR}$ & 2 & 2 & 0 & 0 \\
\hline \multicolumn{5}{|l|}{ Microscopic } \\
\hline $\begin{array}{l}\text { Residuals } \\
\text { in }\end{array}$ & 1 & 1 & 1 & 0 \\
\hline \multicolumn{5}{|l|}{ Primary } \\
\hline \multicolumn{5}{|l|}{ Tumor } \\
\hline \multicolumn{5}{|l|}{ Microscopic } \\
\hline $\begin{array}{l}\text { Residuals } \\
\text { in }\end{array}$ & 1 & 2 & 1 & 0 \\
\hline $\begin{array}{l}\text { Lymph } \\
\text { nodes }\end{array}$ & & & & \\
\hline Total & 4 & 5 & 2 & 0 \\
\hline
\end{tabular}

Where in 11 patients (hormone-receptors positive) who experienced a favorable pathological response which include complete pathological response and microscopic residuals in either the primary tumor or axillary lymph nodes, there were two patients with Her-2/neu positive disease and this finding is more or less matched with that repented by Aguiar et al. ${ }^{22}$ when using Epirubicin, cyclophosphamide and weekly pacliteal as neoadjuvant therapy where they found one case with Her-2/neu positive out of eleven cases with good pathological responses including $\mathrm{pCR}$ and minimal residual disease.

\section{RECOMMENDATIONS}

The combination of docetaxel, doxorubicin and cyclophosphamide with granulocyte colony stimulating factor as given in this study is safe, tolerable and shows good activity in the neoadjuvant setting for locally advanced breast cancer stages IIB to III patients.

\section{REFERENCES}

1. Polychemotherapy for early breast cancer: an overview of the randomised trials. Early Breast Cancer Trialists' Collaborative Group. Lancet 1998 Sep 19;352(9132):930-42.

2. Nabholtz JM, Mackey JR, Smylie M, Paterson A, Noel DR, Al Tweigeri T, et al. Phase II study of docetaxel, doxorubicin, and cyclophosphamide as first -line chemotherapy for metastatic breast cancer. J Clin Oncol 2001 Jan 15;19(2):314-21.

3. Nabholtz JM, Falkson C, Campos D, Szanto J, Martin M, Chan $\mathrm{S}$, et al. Docetaxel and doxorubicin compared with doxorubicin and cyclophosphamide as first-line chemotherapy for metastatic breast cancer: results of a randomized, multicenter, phase III trial. J Clin Oncol 2003 Mar 15;21(6):968-75.

4. Bonadonna G, Valagussa P, Brambilla C, Ferrari L, Moliterni A, Terenziani $\mathrm{M}$, et al. Primary chemotherapy in operable breast cancer: eight-year experience at the Milan Cancer Institute. J Clin Oncol 1998 Jan;16(1):93-100.

5. Fisher B, Bryant J, Wolmark N, Mamounas E, Brown A, Fisher ER, et al. Effect of preoperative chemotherapy on the outcome of women with operable breast cancer. J Clin Oncol 1998 Aug;16(8):2672-85.

6. First report of the European Cooperative Trial in operable breast cancer (ECTO): Effects of Primary systemic therapy (PST) on local-regional disease; 2002.

7. Docetaxel primary chemotherapy in breast cancer: a five-year update of the Aberdeen trial; 2003.

8. Kuerer HM, Newman LA, Smith TL, Ames FC, Hunt KK, Dhingra $\mathrm{K}$, et al. Clinical course of breast cancer patients with complete pathologic primary tumor and axillary lymph node response to doxorubicin-based neoadjuvant chemotherapy. J Clin Oncol 1999 
Feb;17(2):460-469.

9. Seidman AD, Reichman BS, Crown JP, Yao TJ, Currie V, Hakes TB, et al. Paclitaxel as second and subsequent therapy for metastatic breast cancer: Activity independent of prior anthracycline response. J Clin Oncol 1995 May;13(5):1152-59.

10. Hudis CA, Seidman AD, Crown JP, Balmaceda C, Freilich R, Gilewski TA, et al. Phase II and pharmacologic study of docetaxel as initial chemotherapy for metastatic breast cancer. J Clin Oncol 1996 Jan;14(1):58-65.

11. Ravdin PM, Burris HA,3rd, Cook G, Eisenberg P, Kane M, Bierman WA, et al. Phase II trial of docetaxel in advanced anthracycline-resistant or anthracenedione-resistant breast cancer. J Clin Oncol 1995 Dec;13(12):2879-85.

12. Valero V, Holmes FA, Walters RS, Theriault RL, Esparza L, Fraschini G, et al. Phase II trial of docetaxel: A new, highly effective antineoplastic agent in the management of patients with anthracycline-resistant metastatic breast cancer. J Clin Oncol 1995 Dec;13(12):2886-94

13. Singletary SE, Allred C, Ashley P, Bassett LW, Berry D, Bland KI, et al. Revision of the American Joint Committee on Cancer staging system for breast cancer. J Clin Oncol 2002 Sep $1 ; 20(17): 3628-36$

14. National Cancer Institute. Common Toxicity Criteria, Version 2.0. 1999 Apr 30.

15. Ferriere JP, Assier I, Cure H, Charrier S, Kwiatkowski F, Achard JL, et al. Primary chemotherapy in breast cancer: Correlation between tumor response and patient outcome. Am J Clin Oncol 1998 Apr;21(2):117-20.

16. Skipper HE. Kinetics of mammary tumor cell growth and implications for therapy. Cancer 1971 Dec;28(6):1479-99.

17. Chevallier B, Roche H, Olivier JP, Chollet P, Hurteloup P. Inflammatory breast cancer. Pilot study of intensive induction chemotherapy (FEC-HD) results in a high histologic response rate. Am J Clin Oncol 1993 Jun;16(3):223-28.
18. Sataloff DM, Mason BA, Prestipino AJ, Seinige UL, Lieber CP, Baloch Z. Pathologic response to induction chemotherapy in locally advanced carcinoma of the breast: a determinant of outcome. J Am Coll Surg 1995 Mar;180(3):297-6.

19. Honkoop AH, van Diest PJ, de Jong JS, Linn SC, Giaccone G, Hoekman K, et al. Prognostic role of clinical, pathological and biological characteristics in patients with locally advanced breast cancer. Br J Cancer 1998 Feb;77(4):621-26.

20. Smith IC, Heys SD, Hutcheon AW, Miller ID, Payne S, Gilbert FJ, et al. Neoadjuvant chemotherapy in breast cancer: Significantly enhanced response with docetaxel. J Clin Oncol 2002;20(6):145666.

21. Aguiar Bujanda D, Bohn Sarmiento U, Cabrera Suarez MA, Pavcovich Ruiz M, Limeres Gonzalez MA, Aguiar Morales J. Epirubicin, cyclophosphamide and weekly paclitaxel as neoadjuvant chemotherapy for stage II and III breast cancer. J Cancer Res Clin Oncol 2006;132(5):332-38.

22. Green MC, Buzdar AU, Smith T, Ibrahim NK, Valero V, Rosales MF, et al. Weekly paclitaxel improves pathologic complete remission in operable breast cancer when compared with paclitaxel once every 3 weeks. J Clin Oncol 2005 Sep 1;23(25):5983-92.

23. Bear HD, Anderson S, Brown A, Smith R, Mamounas EP, Fisher $B$, et al. The effect on tumor response of adding sequential preoperative docetaxel to preoperative doxorubicin and cyclophosphamide: Preliminary results from National Surgical Adjuvant Breast and Bowel Project Protocol B-27. J Clin Oncol 2003 Nov 15;21(22):4165-74.

24. Kuerer HM, Sahin AA, Hunt KK, Newman LA, Breslin TM, Ames FC, et al. Incidence and impact of documented eradication of breast cancer axillary lymph node metastases before surgery in patients treated with neoadjuvant chemotherapy. Ann Surg 1999 Jul;230(1):72-78.

25. McCready DR, Hortobagyi GN, Kau SW, Smith TL, Buzdar AU, Balch CM. The prognostic significance of lymph node metastases after preoperative chemotherapy for locally advanced breast cancer. Arch Surg 1989 Jan;124(1):21-25. 